\title{
Plasma concentration of nortriptyline as a guide to treatment
}

\author{
W. H. LYLE \\ M.D. \\ P. W. BROOKS \\ M.B., D.P.M., M.R.C.Psych. \\ D. F. EARLY \\ D.P.M., F.R.C.Psych. \\ W. P. Leggett \\ G. Silverman \\ M.B., D.P.M.
}

\author{
R. A. Braithwaite \\ A.R.I.C. \\ J. M. CUThILL \\ M.R.C.P., D.P.M. \\ R. GOULDING \\ M.D., F.R.C.P.
}

I. B. PEARson

M.D., D.P.M., M.R.C.Psych.

R. P. SNAITH

M.D., D.P.M., M.R.C.Psych.

\author{
G. E. Strang \\ M.B., D.P.M.
}

Guy's Hospital, Poisons Unit, London

\begin{abstract}
Summary
Blood samples were collected from forty-five patients with depression who had been taking nortriptyline for at least 14 days. At the time of blood collection the observer recorded his opinion of each patient's response to treatment either as 'satisfactory' or 'unsatisfactory', together with any change in therapy then decided upon. The patients came from six different hospitals but all plasma nortriptyline estimations were performed at a single laboratory. No statistically significant correlation could be discerned between dose or plasma nortriptyline concentration and therapeutic response or decision to change treatment. Under the conditions of general psychiatric practice, the occasional 'spot' estimation of plasma nortriptyline concentrations is unlikely to be a practical guide to the nortriptyline requirements of most patients.
\end{abstract}

\section{Introduction}

Nortriptyline (Allegron, Aventyl) and other drugs of the tricyclic group are now more widely prescribed than any other form of treatment for patients with depression, especially in domiciliary and out-patient practice. The results of treatment are, however, frequently poor (Porter, 1970). Individual patients given a fixed dose of a tricyclic antidepressant drug achieve widely differing 'steady-state' plasma concentrations of the drug (Hammer and Sjöqvist, 1967; Braithwaite and Widdop, 1971). This variability is the result of genetically determined differences in

Correspondence: Dr W. H. Lyle, Dista Products Limited, Speke, Liverpool L24 9LN the rate of drug metabolism sometimes modified inhibit metabolizing enzymes (Hammer, Ideström $\vec{\varphi}$ and Sjöqvist, 1967; Alexanderson, Price-Evans ang $\stackrel{+}{+}$ Sjöqvist, 1969; Gram and Fredricson-Over, 1972总 The relationship between plasma concentrations of these drugs and their antidepressant effects hàs recently been the subject of debate. Asberg et al. $(1971,1973)$ demonstrated a curvilinear relationship between plasma level of nortriptyline and antidepressant effect over 2 and 4 week periods with reduced activity at extremes of plasma concentration.

Similarly, Braithwaite et al. (1972) using amitriptyline, reported a direct relationship between plasma concentrations of the drug and its metabolite nortriptyline, and clinical response. Burrows, Davies and Scoggins (1972), however, found no correlation between plasma concentration of nortriptyline and antidepressant activity. Methodological differences may account for these different findings but for practical purposes, as Burrows, Davies and Scoggins (1973) have indicated, the $\frac{D}{O}$ important question is 'whether knowing the individual patient's plasma tricyclic level is of any $/ 0$ clinical value'. We have addressed ourselves to this $N$ question. Our aim was to determine how closely స్ల single estimations of plasma nortriptyline concentration could be related to (a) the attending physician's opinion about patients' response to treatment, and $\frac{0}{\varnothing}$ (b) decisions about changes in treatment, in the $\stackrel{\mathbb{R}}{\rightarrow}$ course of ordinary day to day outpatient practice in 7 six busy psychiatric clinics; and thus to test the potential value of routine estimations of plasma nortriptyline levels in normal clinical practice. 


\section{Patients and methods}

Forty-five patients with depression severe enough to have led to their being referred to hospital provided the data for analysis. Those who had recently received ECT or who were taking other antidepressant drugs were excluded.

Each clinician was free to prescribe the dose of nortriptyline he thought appropriate and was also free to assess patients at follow-up in whatever way he wished and to record his opinion of their progress at any stage, once they had been taking nortriptyline for at least 2 weeks.

At the time of assessment for the purposes of this study the attending clinician recorded his opinion of each patient's progress with respect to relief of symptoms of depression as 'satisfactory' or 'unsatisfactory'. He also recorded any decision to change the treatment. At the same time blood was collected for nortriptyline estimation.

A standard record form was used and upon this were recorded each patient's age, weight, dose of nortriptyline prescribed, any other therapy given, side effects reported, opinion about progress and reason for withdrawal where appropriate.

Ten millilitres of blood were collected into lithium heparin tubes, centrifuged at the respective hospital laboratories for $5 \mathrm{~min}$ at $3000 \mathrm{rev} / \mathrm{min}$, aspirated into fresh tubes and despatched to the Poisons Unit in London where the samples were deep frozen until analysed. It had been previously demonstrated (Braithwaite and Widdop, 1971) and was again confirmed that nortriptyline contained in plasma samples did not decline even after prolonged storage at room temperature.

Plasma nortriptyline assays were carried out by a specific gas-chromatographic method (Braithwaite and Widdop, 1971) in ignorance of the clinical data from the patients. Spot checks of urine for the presence of other drugs were also carried out.

\section{Results}

Detailed results for the forty-five patients in the study are presented in Table 1 . Thirty-one of the patients were women, average age 41 , and fourteen were men, average age 38 , the age range of the entire group being from 20 to 77 years.

Nortriptyline was prescribed in daily doses which varied from $55-200 \mathrm{mg}$, almost half the patients being given substantially larger doses than the 75-100 mg daily advocated by the manufacturer.

Clinical assessment and blood collection were carried out at various times after the patients began to take nortriptyline, from 14 to 56 days. Thirty patients were considered at the time of blood collection to have been making 'satisfactory' progress. Of the patients in the 'satisfactory' group, one had her dose of nortriptyline reduced, the others con- tinuing as before. Only in one instance was 'unsatisfactory' progress the result of adverse reaction in this patient and no change in dose was ordered. The other fourteen were all judged to be gaining less benefit from nortriptyline than was expected and changes in the antidepressant regimen were made for thirteen of these patients. The drug was withdrawn in six instances, the dose increased in five, and ECT prescribed in addition to nortriptyline in two.

Plasma nortriptyline concentrations in this group of patients ranged from $44 \mathrm{ng} / \mathrm{ml}$ to $305 \mathrm{ng} / \mathrm{ml}$ (Fig. 1).

Barbiturate, which had not been prescribed at the clinic, was detected in the urine of three patients, one of whom was the patient whose 'unsatisfactory' response to treatment was attributed to adverse reaction and whose plasma nortriptyline concentration was less than $20 \mathrm{ng} / \mathrm{ml}$.

\section{Dose and plasma concentration of nortriptyline}

The relationship between the daily dose $(\mathrm{mg} / \mathrm{kg})$ and plasma concentration $(\mathrm{ng} / \mathrm{ml})$ is shown in Fig. 2 for the forty-one patients for whom the complete data are available. Plasma concentrations tend to be higher among the patients given the larger daily doses but much scatter is apparent.

\section{Clinical response, dose and plasma concentration of nortriptyline}

The lack of an optimum dose $(\mathrm{mg} / \mathrm{kg})$ of nortriptyline is demonstrated in Fig. 3.

The relationship of plasma nortriptyline concentration to clinical response is shown in Fig. 4. Again there is no evidence of an optimum plasma nortriptyline concentration, patients showing 'unsatisfactory' response and 'satisfactory' response to treatment over the same range of plasma concentrations, from less than $20 \mathrm{ng} / \mathrm{ml}$ to over $300 \mathrm{ng} / \mathrm{ml}$.

\section{Effect of observers}

Five of the psychiatrists taking part in this study personally supervised at least seven patients (Table 1). Dr A. had a more youthful group of patients than the rest. Dr B. and Dr F. had considered women only.

Dr B. used rather higher doses and Dr G. rather lower doses of nortriptyline than the rest. Dr A., Dr B. and Dr G. each found that seven of their patients were progressing satisfactorily and that only one or two were not, whereas Dr E. and Dr F. each found that only three of their patients were responding satisfactorily to the drug while four were not. The opinions and decisions of all bore no discernible relationship to plasma nortriptyline concentrations in their patients. 


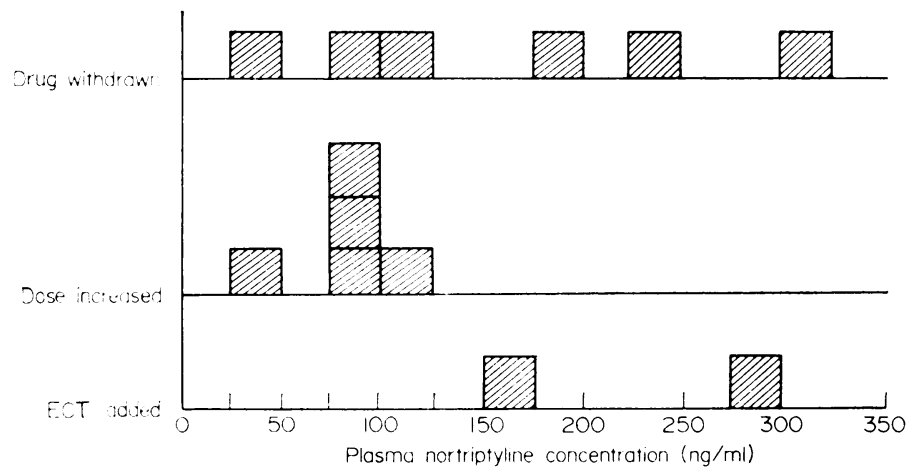

Fici. 1. Concentration of nortriptyline in plasma at which changes in antidepressant therapy were ordered because of lack of nortriptyline effect. W/, one patient; $\mathrm{n}=13$. Each square block represents one patient.

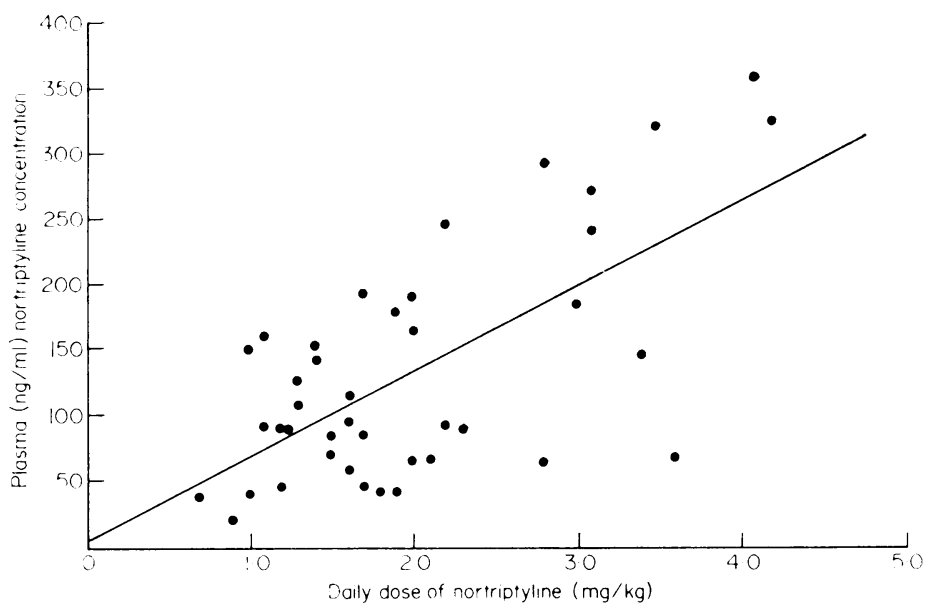

FIci. 2. Relationship of daily dose $(\mathrm{mg} / \mathrm{kg})$ to plasma concentration of nortriptyline. $y \quad 4 \cdot 1 \quad 64 \cdot 7 x ; r \quad 0.66 ; n \quad 41$.

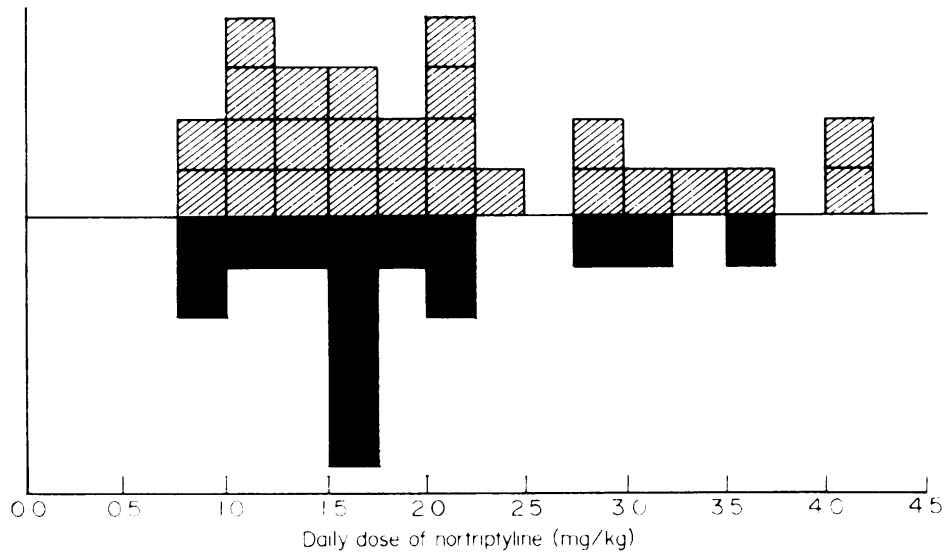

FIci. 3. Numbers of patients making 'satisfactory' or 'unsatisfactory' progress in response to particular doses of nortriptyline. $\mathbb{Z}$. one patient with a 'satisfactory" response; $n \quad 26$. n 15. Each square block represents one patient. 
TABLE 1. Assessment of clinical response to nortriptyline by forty-five patients, in relation to observer, dose and duration of treatment and concentration or nortriptyline in plasma

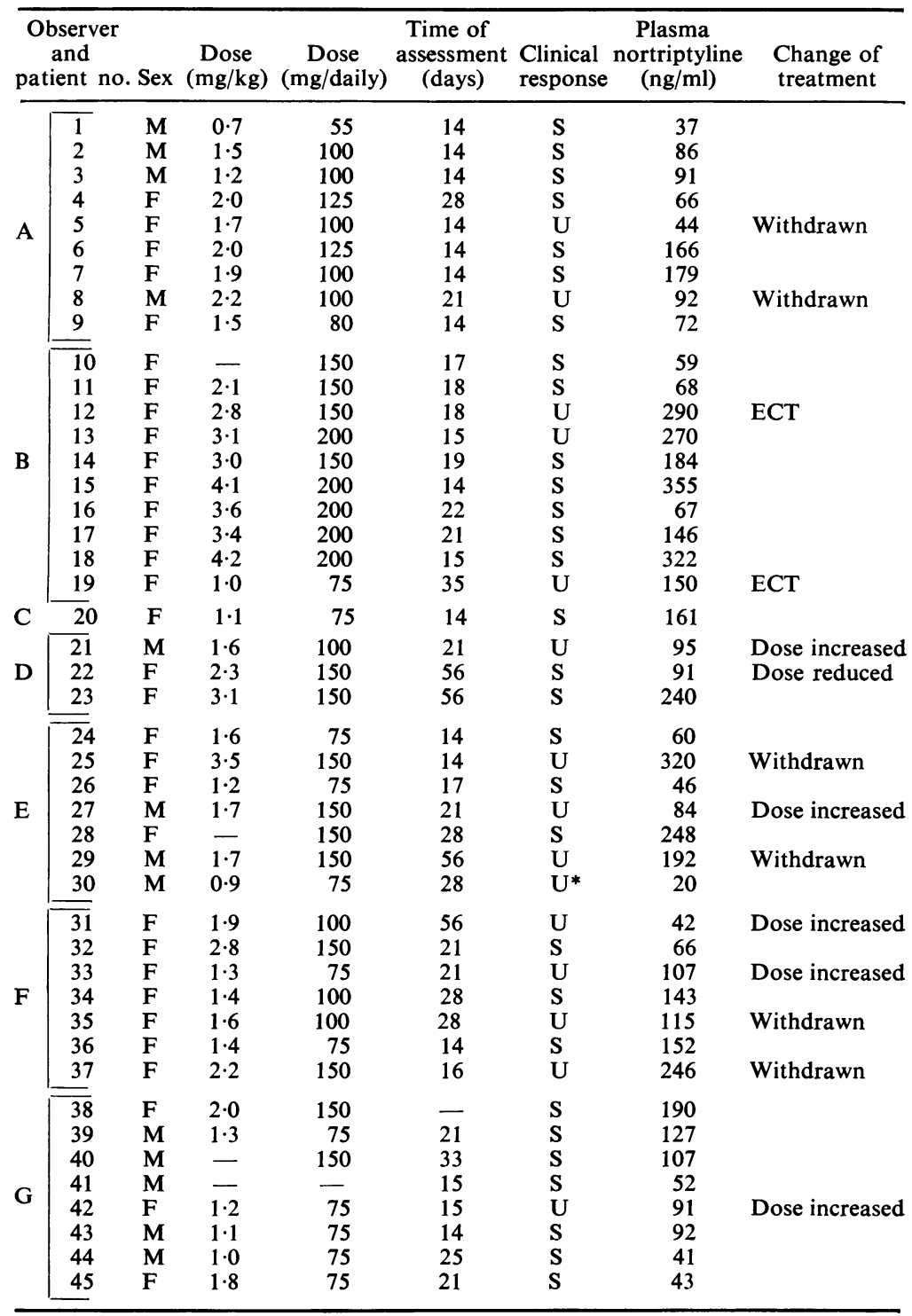

* Side effects, phenobarbitone in urine 


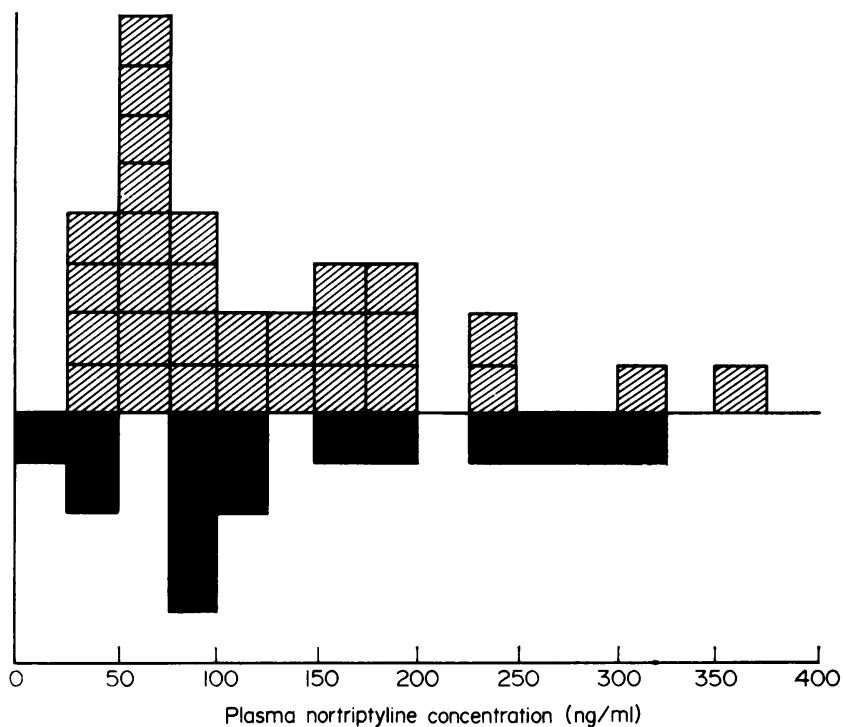

FIG. 4. Numbers of patients making 'satisfactory' or 'unsatisfactory' progress at particular concentrations of nortriptyline in plasma. $\mathscr{G}$, one patient with a 'satisfactory' response; $n=30 ; \square$, one patient with an 'unsatisfactory' response. Each square block represents one patient.

\section{Discussion}

The wide range of plasma nortriptyline concentrations observed in our patients given similar doses of nortriptyline confirms previously published findings, as also does the lack of correlation between dosage and therapeutic response (Asberg et al., 1971).

We did not find a correlation between plasma nortriptyline concentrations and a 'satisfactory' therapeutic response. This is in general agreement with the findings of Burrows and his colleagues (1972), who had given a standard dose of $150 \mathrm{mg}$ of nortriptyline daily to thirty-two patients for at least 4 weeks. Our findings conflict with those of Asberg et al. (1971) and Kragh-Sørensen et al. (1973) showing a correlation between plasma nortriptyline concentrations and therapeutic response. Our results also conflict with the findings for amitriptyline obtained by Braithwaite et al. (1972) where a highly significant positive correlation between plasma levels and therapeutic response was obtained. However, for several reasons our respective studies are not strictly comparable.

We assessed patients on a simple 'all or none' principle on a single occasion whereas in the other studies rating scales for depression were used repeatedly in individual subjects. We made no attempt to distinguish endogenous from reactive depression; we assessed patients as we saw fit and not in a standardized way; and we could not be certain how closely these outpatients adhered to the prescribe regimen, which itself varied considerably.

The interval between the patient's last dose and collection of blood was also unknown. The apparent lack of correlation between plasma nortriptyline concentration and clinical response in the group as a whole doubtless is the result of this profusion of uncontrolled variables.

The aim of our study was, however, not to confirm or refute the reported correlation of plasma nortriptyline levels and antidepressant effect in carefully selected groups of patients, but to determine whether 'spot' estimations of nortriptyline concentrations in plasma were likely to provide a useful guide to dosage for individual patients suffering from depression. For such to be the case there should be a substantial degree of agreement between therapeutic response, as judged under the usual conditions of follow-up in clinics and surgeries, and particular concentrations of nortriptyline in the plasma of individuals. None was found.

The most striking demonstration of the inadequacy of plasma nortriptyline estimations as a guide to therapy in our series of patients is provided by the total lack of correlation between the results of such estimations and contemporaneous decisions to change treatment because of inadequate response.

\section{Conclusions}

Under the usual conditions of psychiatric 
outpatient (or general) practice, such as obtained in this experiment, routine 'spot' estimation of plasma nortriptyline concentrations is unlikely to be a practical guide to the nortriptyline requirements of most patients.

Dista Products Ltd, Speke, Liverpool L24 9LN (W.H.L. \& W.P.L.); Guy's Hospital, Poisons Unit, London (R.A.B. \& R.G.); The Royal Edinburgh Hospital, Edinburgh E10 5LG (P.W.B.); Morgannwg Hospital, Bridgend, Glamorgan (J.M.C.); Glenside Hospital, Bristol BS16 1DD (D.F.E.); Whiteley Wood Clinic, Sheffield S10 3TL (I.B.P. \& G.S.); Stanley Royd Hospital, Wakefield (R.P.S.); Rubery Hill Hospital, Birmingham B45 9BB (G.E.S.).

\section{Acknowledgments}

We thank Mr E. Essex for his skilful technical assistance and $\mathrm{Dr}$ B. Widdop for his invaluable advice throughout the study.

\section{References}

Alexanderson, B., Price-Evans, D.A. \& Suoqvist, F. (1969) Steady state plasma levels of Nortriptyline in twins; influence of genetic factors and drug therapy. British Medical Journal, 4, 764.

Asberg, M., Cronholm, B., Suoqvist, F. \& Tuck, D. (1971) Relationship between plasma level and therapeutic effect of Nortriptyline. British Medical Journal, 3, 331.

Braithwaite, R.A., Goulding, R., Theano, G., Bailey, J. \& Coppen, A. (1972) Plasma concentrations of Amitriptyline and clinical response. Lancet, i, 1297.

Braithwaite, R.A. \& Widdop, B. (1971) A specific gaschromatographic method for the measurement of 'steady state' plasma levels of Amitryptyline and Nortriptyline in patients. Clinica Chimica Acta, 35, 461 .
Burrows, G.D., Davies, B. \& Scoggins, B.A. (1972) Plasma concentration of Nortriptyline and clinical response in depressive illness. Lancet, ii, 619.

Burrows, G.D., Davies, B. \& Scoggins, B.A. (1973) Clinical significance of plasma levels of tricyclic antidepressant drugs in the treatment of depression. Lancet, $\mathbf{i}$, 557.

Gram, L.F. \& Fredricson-Overø, K. (1972) Drug interaction: Inhibitory effect of neiroleptics on metabolism of tricyclic antidepressants in man. British Medical Journal, 1, 463.

Hammer, W., Idestrom, C-M. \& Sjoqvist, F. (1967) Chemical control of antidepressant drug therapy. Excerpta Medica International Congress Series, 122, 301.

Hammer, W., Martens, S. \& SJoqvist, F. (1969) A comparative study of the metabolism of Desmethylimpramine, Nortriptyline and Oxyphenylbutazone in man. Clinical Pharmacology and Therapeutics, 10, 44.

Hammer, W. \& SJoqvist, F. (1967) Plasma levels of monomethylated tricyclic antidepressants during treatment with Imipramine like compounds. Life Science, 6, 1895.

Kragh-Sørensen, P., Asberg, M. \& Eggert-Hansen, C. (1973) Plasma Nortriptyline levels in endogenous depression. Lancet, i, 113.

Moody, J.P., TAIT, A.C. \& Todrick, A. (1967) Plasma levels of Imipramine and Desmethylimpramine during therapy. British Journal of Psychiatry, 113, 183.

Porter, A.M.W. (1970) Depressive illness in a General Practice. A demographic study and a controlled trial of Imipramine. British Medical Journal, 1, 773.

SJoqvist, F., Hammer, W., Idestrom, C-M., Lind, M., TuCK, D. \& Asberg, M. (1967) Plasma level of monomethylated tricyclic antidepressants and side effects in man. Excerpta Medica International Congress Series, 145, 246. 